\title{
Doku tiplendirme laboratuvarına gönderilmiş olan örneklerde HLA antijenlerinin dağılımının araştırılması
}

\author{
Study of HLA antigen distributions in samples sent in a tissue typing laboratory
}

Ergun Mete

Gönderilme tarihi:27.05.2021

Kabul tarihi:01.06.2021

\section{Öz}

Amaç: Bu çalışmada, Sağlık Araştırma ve Uygulama Merkezi Doku Tipleme Laboratuvarına başvuran kişilerde HLA sınıf I ve sınıf II allel sıklığının belirlenmesi ve HLA genotipleme sonuçlarının değerlendirilmesi amaçlanmıştır. Gereç ve yöntem: Çalışmamızda toplam 1903 kişinin verileri incelenmiş ve HLA sınıf I ve II allel sıklığı hesaplanmıştır. HLA A, B ve DRB1 allelleri tüm örneklerde, HLA C ve DQB1 alleleri 493 kişide çalışılmıştır. Değerlendirmeye alınmış olan kişilerin \%57,4'ü erkek, \%42,3'ü kadındır. Tam kan örneklerinden genomik DNA izolasyonu otomatize sistem (EZ1 Advanced, QIAGEN, Hilden, Almanya) kullanılarak yapılmıştır. HLA allellerinin belirlenmesi PCR-SSO (squence spesific oligonucleotid) yöntemi ile Luminex 200 sistemi (Luminex, Austin, ABD) kullanılarak yapılmıştır.

Bulgular: En sık tespit ettiğimiz HLA A allelleri HLA-A*02 (\%22,3), HLA-A*24 (\%17,1) ve HLA-A*03 $(\% 10,5)$ şeklinde sıralanmıştır. En sık görülen HLA-B allelleri; HLA-B*35 $(\% 16,3)$, HLA-B*51 $(\% 15,2)$ ve HLA-B*44 $(\% 8,3)$ olarak tespit edilmiştir. HLA-C allelleri; HLA-C*04 $(\% 19,1)$, HLA-C*07 $(\% 16,0)$ ve HLA-C*12 $(\% 15,0)$ olarak tespit edilmiştir. HLA-DRB1 allelleri; HL- DRB1*11 (\%19,9), HLA DRB1*04 (\%17,7) ve HLA- DRB1*15 (\%10,5), HLA-DQB1 allelleri; HLA-DQB1*03 (\%40,9), HLA-DQB1*05 (\%25,7) ve HLA-DQB1*06 $(\% 18,3)$ olarak saptanmıştır.

Sonuç: Bulgularımız ülkemizde yapılan diğer çalışmalarla tanımlanan HLA antijenleri ile karşılaştırıldığında bazı farklılıklarla beraber büyük ölçüde uyumludur. Bu çalışma bölgemizdeki HLA allel frekans verilerine ve HLA çeşitliliğinin belirlenmesine katkı sağlayacaktır.

Anahtar kelimeler: Transplantasyon, HLA, sınıf I, sınıf II.

Mete E. Doku tiplendirme laboratuvarına gönderilmiş olan örneklerde HLA antijenlerinin dağılımının araştırılması. Pam Tıp Derg 2021;14:742-746.

\begin{abstract}
Purpose: In this study, it was aimed to determine the frequency of HLA class I and class II alleles and to evaluate the results of HLA genotyping in people who applied to the Health Research and Application Center Tissue Typing Laboratory.

Material and method: In our study, the data of 1903 patients were examined and the HLA class I and II allele frequencies were calculated. HLA A, B and DRB1 alleles were studied in 1903 individuals, HLA C and DQB1 alleles were studied in 493 individuals. $57.4 \%$ of the subjects were male and $42.3 \%$ were female. Genomic DNA isolation from whole blood samples was performed using an automated system (EZ1 Advanced, QIAGEN, Hilden, Germany). For the determination of HLA alleles, PCR-SSO (squence specific oligonucleotide) method and Luminex 200 system (Luminex, Austin, USA) were used. PCR-SSO (squence specific oligonucleotide) method was used to identify HLA alleles.

Results: The most common HLA-A alleles were HLA-A*02 (22.3\%), HLA-A*24 (17.1\%), and HLA-A*03 (10.5\%). The most common HLA-B alleles were HLA-B*35 (16.3\%), B*51 (15.2\%), and $B * 44(8.3 \%)$. HLA-C alleles; HLA-C*04 (19.1\%), HLA-C*07 (16.0\%), and HLA-C*12 (15.0\%). HLA-DRB1 alleles; HLA-DRB1*11 (19.9\%), HLA-DRB1*04 (17.7\%), and HLA-DRB1*15 (10.5\%). HLA-DQB1 alleles; HLA-DQB1 03 (40.9\%), HLA-DQB1*05 (25.7\%), and HLA-DQB1*06 (18.3\%).

Conclusion: Our findings are mostly consistent with some differences when compared with HLA antigens identified in other studies conducted in our country. This study will contribute to the HLA allele frequency data and the determination of HLA diversity in our region.
\end{abstract}

Key words: Transplantation, HLA, class I, class II.

Mete E. Study of HLA antigen distributions in samples sended in a tissue typing laboratory. Pam Med $\mathrm{J}$ 2021;14:742-746. 


\section{Giriş}

Günümüzde transplantasyonların artan bir sıklıkta yapılması nedeniyle doku grubu tayinlerinin önemi artmaktadır. İnsan majör doku uyumu kompleksi (MHC)'ne insan lökosit antijeni (HLA) genleri denir. HLA'yı kodlayan gen bölgesi, insanda 6 . Kromozomun kısa kolu üzerinde bulunur [1].

MHC (majör doku uyumu kompleksi), bağışıklık ile ilgili fonksiyonları olan ve olmayan molekülleri kodlayan çeşitli bir gen grubudur. HLA'lar, insan MHC bölgesi tarafından ifade edilen glikoproteinlerdir [2].

Majör doku uygunluk kompleksi (MHC) molekülleri ya da diğer adıyla insan lökosit antijenleri (HLA) T hücrelerine antijen sunup onları aktive eden ve $T$ hücre aracılı immün yanıtınn yönünü belirleyen hücre yüzey molekülleridir. Bu moleküller özgünlüğü yüksek olmayan ve self antijen yabancı antijen ayrımı yapamayan moleküllerdir. Antijene özgün immün yanıt oluşmasında özgünlüğü oluşturan faktör HLA molekülü değil T hücresinin kendisidir [3].

HLA, kodlanan proteinlerin özelliklerine göre Sınıf I, II, III olarak alt bölgelere ayrılır. Doku uygunluk antijenleri olarak adlandırılan Sınıf I ve II proteinleri T hücrelerine antijen sunumundan sorumludurlar. Doku atıımını belirleyenler Sınıf I (HLA- A, B, C) ve sınıf II (HLA-DP, DR, DQ) molekülleri olarak tanımlanmıştır $[4,5]$.

HLA allellerinin frekansları, farklı popülasyonlar arasında önemli farklılıklar gösterir. HLA çeşitliliği, bireyler arasında önemli immünolojik farklılıklara neden olur. HLA gen bölgesi yüksek oranda polimorfik bir bölge olup, bugüne kadar sınıf I HLA alleleri 21903 ve sınıf II alleleri 8136 olmak üzere toplam 30,522 HLA alleli bildirilmiştir ve bu sayı artmaya devam etmektedir [6].

HLA sınıf I moleküllerinin görevi virüsler, tümör antijenleri gibi intrasitoplazmik antijenleri CD8+ sitotoksik $T$ hücrelerine sunmaktır. Sınıf II molekülleri ise endositozla alınan bakterileri CD4+ yardımcı T hücrelerine sunar [3].

HLA molekülleri organizmanın en polimorfik genlerinin yer aldığı dev bir kompleks olan HLA(MHC) gen bölgesinde kodlanır. Yüksek polimorfizm özeliğine ek olarak, kodominant kalıtım göstermesi ve bu genlerdeki mutasyonların devam ediyor olması toplumdaki bireyler arasında immünolojik olarak yüksek düzeyde çeşitlilik oluşmasına neden olmaktadır. Bunun evrimsel olarak önemi dünya üzerindeki yaşamın kesintisiz olarak devam etmesini sağlamaktır. Ancak diğer taraftan yaratılan bu immünolojik çeşitlilik bireyler arasında enfeksiyonlarla mücadelede ve otoimmünalerjik hastalıklara yatkınlıkta önemli farklar oluşmasına neden olmaktadır $[7,8]$.

Ek olarak, belirli HLA allellerine sahip bireyler arasında bazı hastalıkların daha yüksek prevalansa sahip olduğu tespit edilmiştir. HLA-B27 Ankilozan spondilit ile HLA-B51 Behçet hastalığı ile ve HLA-DQ2/DQ8 çölyak hastalığı ile ilişkilidir [9-11]. HLA molekülleri ayrıca aşıların geliştirilmesi ve etkinliğini etkiler ve transplantasyonun sonuçlarında belirleyici bir rol oynar. Organ/doku nakli planlanan alıclvericiler için HLA-A,B ve DR lokus alellerinin tiplendirilmesi gerekir. Hemopoetik kök hücre naklinde bu lokus sayısının artı̆ğı (HLA-A, -B, -C, -DR, -DQ gibi) görülür [12].

Bu çalışmada 2013-2018 yılları arasında Sağlık Araştırma ve Uygulama Merkezi Doku Tipleme Laboratuvarı tarafından test edilen bireylerde HLA allel sıklığının belirlenmesi ve HLA genotipleme sonuçlarının değerlendirilmesi amaçlanmıştır.

\section{Gereç ve yöntem}

$\mathrm{Bu}$ çalışma retrospektif olarak yapılmıştır. Çalışmamızda toplam 1903 kişinin sonuçları incelenmiş ve HLA sınıf I ve II allel sıklığı hesaplanmıştır. HLA A, B ve DRB1 allelleri tüm örneklerde, HLA C ve DQB1 alleleri 493 kişide çalışıımıştır. Değerlendirmeye alınmış olan kişilerin \%57,4'ü erkek, \%42,3'ü kadındır. Tam kan örneklerinden genomik DNA izolasyonu otomatize sistem (EZ1 Advanced, QIAGEN, Hilden, Almanya) kullanılarak yapılmıştır. HLA allellerinin belirlenmesi PCR-SSO (squence spesific oligonucleotid) yöntemi ile Luminex 200 sistemi kullanılarak yapılmıştır. (Luminex, Austin, ABD). SSO yöntemi ile genellikle bir HLA lokusunun PCR ile çoğaltılmasını takiben alellere özgün olan oligonukleotidler kullanılarak bu çoğalmış DNA segmenti ile özgün oligonukleotidlerin katı bir ortam üzerinde hibridizasyon sonucunda bireyin hangi HLA alellini taşıdığı gösterilmiş olur. 
Çalışma için, Pamukkale Üniversitesi Tıp Fakültesi Girişimsel Olmayan Klinik Araştırmalar Etik Kurulu'ndan etik onayı alınmıştır.

\section{Bulgular}

En sık tespit ettiğimiz HLA-A allelleri HLA-A*02 (\%22,3), HLA-A*24 (\%17,1) ve HLA-A*03 $(\% 10,5)$ şeklinde sıralanmıştır. En sık görülen HLA-B allelleri; HLA-B*35 (\%16,3), $B * 51(\% 15,2)$ ve $B^{*} 44(\% 8,3)$ olarak, HLA-C allelleri; HLA C*04 (\%19,1), C*07 (\%16,0) ve C*12 $(\% 15,0)$ olarak tespit edilmiştir. HLA sınıf-I allelerinin dağılımı Tablo 1'de gösterilmiştir.

HLA-DRB1 allelleri; HLA-DRB1*11 (\%19,9), HLA-DRB1 ${ }^{* 04}(\% 17,7)$ ve HLA-DRB1*15 (\%10,5), HLA-DQB1 allelleri; DQB1*03 (\%40,9), DQB1*05 $(\% 25,7)$ ve DQB1*06 $(\% 18,3)$ olarak saptanmıştır. HLA sınıf-II allelerinin dağılımı Tablo 2'de gösterilmiştir.

Tablo 1. HLA sınıf-I allelerinin dağılımı

\begin{tabular}{|c|c|c|c|c|c|}
\hline HLA-A & $\%$ & HLA-B & $\%$ & HLA-C & $\%$ \\
\hline$A^{*} 01$ & 8,6 & $\mathrm{~B}^{*} 04$ & 0,03 & $C * 01$ & 4,4 \\
\hline$A^{*} 02$ & 22,3 & $\mathrm{~B}^{*} 07$ & 4,8 & $C^{*} 02$ & 2,9 \\
\hline$A^{*} 03$ & 10,5 & $\mathrm{~B}^{*} 08$ & 3,0 & $C^{*} 03$ & 6,8 \\
\hline$A^{*} 11$ & 8,8 & $\mathrm{~B}^{*} 12$ & 0,09 & $C^{*} 04$ & 19,1 \\
\hline$A^{*} 13$ & 0,03 & $B^{* 13}$ & 4,4 & $C * 05$ & 3,5 \\
\hline$A^{*} 14$ & 0,03 & $\mathrm{~B}^{*} 14$ & 1,9 & $C^{*} 06$ & 8,3 \\
\hline$A^{*} 23$ & 2,9 & $B^{*} 15$ & 4,3 & $C^{*} 07$ & 16,0 \\
\hline$A^{*} 24$ & 17,1 & $\mathrm{~B}^{*} 18$ & 5,9 & $C^{*} 08$ & 2,5 \\
\hline$A^{*} 25$ & 0,6 & $\mathrm{~B}^{*} 22$ & 0,03 & $C * 11$ & 0,7 \\
\hline$A^{*} 26$ & 6,4 & $B^{*} 24$ & 0,03 & $C * 12$ & 15,0 \\
\hline$A^{*} 29$ & 2,4 & $\mathrm{~B}^{\star} 27$ & 2,1 & $C^{* 13}$ & 0,3 \\
\hline$A^{*} 30$ & 4,6 & $\mathrm{~B}^{*} 32$ & 0,03 & $C^{*} 14$ & 4,3 \\
\hline$A^{*} 31$ & 2,2 & $\mathrm{~B}^{*} 33$ & 0,03 & $C * 15$ & 9,3 \\
\hline$A^{*} 32$ & 4,8 & $B^{*} 34$ & 0,03 & $C^{*} 16$ & 4,4 \\
\hline$A^{*} 33$ & 2,4 & $B * 35$ & 16,3 & $C^{* 17}$ & 1,7 \\
\hline$A^{*} 34$ & 0,1 & $\mathrm{~B}^{\star} 37$ & 0,9 & $C * 18$ & 0,4 \\
\hline$A^{*} 37$ & 0,03 & $B * 38$ & 5,6 & $C * 43$ & 0,1 \\
\hline$A^{*} 51$ & 0,03 & $\mathrm{~B}^{*} 39$ & 1,8 & $C * 52$ & 0,2 \\
\hline$A^{*} 60$ & 0,03 & $B^{*} 40$ & 4,0 & & \\
\hline$A^{*} 62$ & 0,03 & $\mathrm{~B}^{*} 41$ & 1,8 & & \\
\hline$A^{*} 66$ & 0,4 & $B^{*} 42$ & 0,03 & & \\
\hline$A^{*} 68$ & 5,0 & $\mathrm{~B}^{*} 44$ & 8,3 & & \\
\hline$A^{*} 69$ & 0,7 & $B^{*} 45$ & 0,3 & & \\
\hline \multirow[t]{14}{*}{$A^{*} 74$} & 0,06 & $\mathrm{~B}^{*} 46$ & 0,4 & & \\
\hline & & $B^{*} 47$ & 0,09 & & \\
\hline & & $\mathrm{B}^{*} 48$ & 0,8 & & \\
\hline & & $B^{*} 49$ & 3,4 & & \\
\hline & & $B^{*} 50$ & 2,6 & & \\
\hline & & $B * 51$ & 15,2 & & \\
\hline & & $\mathrm{B}^{*} 52$ & 3,7 & & \\
\hline & & $B^{*} 53$ & 0,6 & & \\
\hline & & $B^{*} 54$ & 0,3 & & \\
\hline & & $B * 55$ & 3,2 & & \\
\hline & & $\mathrm{B}^{*} 56$ & 0,7 & & \\
\hline & & $\mathrm{B}^{*} 57$ & 1,3 & & \\
\hline & & $B^{*} 58$ & 1,8 & & \\
\hline & & $\mathrm{B}^{*} 73$ & 0,2 & & \\
\hline
\end{tabular}


Tablo 2. HLA sınıf II allellerinin dağılımı

\begin{tabular}{llll}
\hline DRB1 & $\%$ & DQB1 & $\%$ \\
\hline DRB1*01 & 6,6 & DQB1*02 & 12,2 \\
DRB1*02 & 0,09 & DQB1*03 & 40,9 \\
DRB1*03 & 7,1 & DQB1*04 & 2,6 \\
DRB1*04 & 17,7 & DQB1*05 & 25,7 \\
DRB1*05 & 0,2 & DQB1*06 & 18,3 \\
DRB1*06 & 0,09 & DQB1*10 & 0,1 \\
DRB1*07 & 7,5 & DQB1*15 & 0,1 \\
DRB1*08 & 1,7 & DQB1*16 & 0,1 \\
DRB1*09 & 1,1 & & \\
DRB1*10 & 2,0 & & \\
DRB1*11 & 19,9 & & \\
DRB1*12 & 1,6 & \\
DRB1*13 & 9,6 & \\
DRB1*14 & 7,6 & \\
DRB1*15 & 10,5 & \\
DRB1*16 & 6,7 & \\
DRB1*17 & 0,03 & \\
DRB1*26 & 0,03 & \\
DRB1*78 & 0,03 & \\
\hline
\end{tabular}

\section{Tartışma}

$\mathrm{Bu}$ çalışmada en sık tespit ettiğimiz HLA-A allelleri HLA-A*02 (\%22,3), HLA-A*24 (\%17,1) ve HLA-A*03 $(\% 10,5)$ şeklinde sıralanmıştır.

Pala ve ark. [13] Trakya bölgesinde yaptıkları çalışmalarında bizim çalışmamızdakine benzer şekilde en sık rastlanan alleli $A^{*} 02$ (\%20 ,5) olarak bulmuşlardır. Bununla birlikte 2. sıklıkla buldukları $A^{* 11}(\% 13,3)$ alleli bizim çalışmamızda çok daha düşük oranda $(\% 8,8)$ bulunmuştur. Adana'da yapılan bir diğer çalışmada ise; en sık tespit edilen HLA-A allelleri HLA-A2 $(\% 29,5)$, HLA-A1 $(\% 21,8)$ ve HLA-A3 $(\% 17,7)$ şeklinde sıralanmıştır [14]. Bu grubun 2.sıklıkla buldukları HLA-A1 $(\% 21,8)$ bizim çalışmamıza göre $(\% 8,6)$ oldukça yüksek orandadır.

Kayhan ve ark.'nın [15] yaptığı çalışmada ise HLA-A gruplarında en sık görülen görülen allellerin HLA-A* 02, 24, 11 olduğu bildirilmiştir. $\mathrm{Bu}$ çalışmanın HLA-A*11 allelinin görülme sıklığının bizim HLA11 sonucuna göre daha yüksek olduğu saptanmıştır.
Ayrıca çalışmamızda ki $A^{*} 02, A^{*} 24, A^{*} 03$ sıralamasının, A lokus antijenleri için daha önce toplumumuzla ilgili yapılan diğer çalışmalarla uyumlu olduğu görülmektedir [16-20].

Bu çalışmada en sık görülen HLA-B allelleri; HLA-B*35 (\%16,3), B*51 (\%15,2) ve $B^{*} 44$ $(\% 8,3)$ diğer çalışmaların çoğu ile uyumlu olmasına karşın Pala ve ark. [13] yaptıkları çalışmada $B^{*} 07(\% 8,1)$ allelinin daha yüksek olduğu dikkati çekmiştir. Bizim çalışmamızda ise $B^{*} 07$ allelinin görülme sıklığı \%4,8'dir.

Çalışmamızda HLA-DRB1 allelleri; HLADRB1*11 (\%19,9), HLA-DRB1*04 (\%17,7) ve HLA-DRB1*15 (\%10,5) olarak bulunmuştur. HLA-DRB1 sonuçları diğer çalışmalarla genel olarak uyumlu olmasına karşın yine Pala ve ark.'nın [13] sonuçlarının farklı olduğu görülmektedir. Pala ve ark. [13] HLA-DRB1*13 $(\% 13,3)$ allelini 2. sıklıkla bulmuşlardır. Bizim çalışmamızda bu allel daha düşük orandadır $(\% 9,6)$. Bu farklılıkların genetik nedenlerle olabileceğini düşünmekteyiz. 
HLA-C ve HLA-DQ sonuçlarımız diğer çalışmalarla uyumludur.

Sonuçlarımız ülkemizde yapılan diğer çalışmalarda tanımlanan HLA antijenleri ile karşılaştırıldığında bazı farklılıklar göstermesine karşın büyük ölçüde uyumluydu. Çalışmamızın sonuçlarının bölgemizdeki HLA allel frekans verilerine veHLAçeşitliliğinin belirlenmesinekatkı sağlayacağı düşünülmektedir. Bizim verilerimizin ve diğer ulusal verilerin birlikte değerlendirilmesi doku uyumluluğunun çok önemli olduğu kemik iliği donör seçiminin kolaylaştırması açısından büyük önem taşımaktadır. Ayrıca daha ileri HLA polimorfizmleri ve antropolojik çalışmalara katkıda bulunabilir. HLA allel frekanslarını daha iyi anlamanın ulusal transplantasyon stratejilerinin oluşturulmasına yardımcı olacağı düşünülmektedir.

Çıkar ilişkisi: Yazar çıkar ilişkisi olmadığını beyan eder.

\section{Kaynaklar}

1. Yılmaz M. Histocompatibility antigens. Archives Medical Review Journal 2014;23:8-13. https://doi. org/10.17827/aktd.79536

2. Abbas KA, Andrew HL, Pillai S. Cellular and molecular Immunology. Philadelphia: Saunders Elsevier: 2007.

3. Wieczorek M, Abualrous ET, Sticht J, et al. Major Histocompatibility Complex (MHC) class I and MHC class II proteins: conformational plasticity in antigen presentation. Front Immunol 2017;8:292. https://doi. org/10.3389/fimmu.2017.00292

4. Shiina T, Hosomichi K, Inoko H, Kulski JK. The HLA genomic loci map: expression, interaction, diversity and disease. J Hum Genet 2009;54:15-39. https://doi. org/10.1038/jhg.2008.5

5. Montgomery RA, Tatapudi VS, Leffell MS, Zachary AA. HLA in transplantation. Nat Rev Nephrol 2018;14:558570. https://doi.org/10.1038/s41581-018-0039-x

6. Nomenclature for factors of the HLA system. Available at: http://hla.alleles.org/nomenclature/index.html. [Date last updated: March 2021] Accessed April 15, 2021

7. Özbolat G, Dündar Yenilmez E, Tuli A. İnsan lökosit antijenleri, yapı ve işlevleri. Archives Medical Review Journal 2014;23:387-397. https://doi.org/10.17827/ aktd.97054

8. Goldberg AC, Rizzo LV(2015). MHC structure and function - antigen presentation. Part 1. Einstein (Sao Paulo) 2015;13:153-156. https://doi.org/10.1590/ S1679-45082015RB3122

9. Xi Y. HLA and associated important diseases. IntechOpen: 2014. https://doi.org/10.5772/57022
10. Yalçın B. Major doku uygunluk kompleksi (MHC) molekülleri: genel özellikleri ve hastalıklarla ilişkisi. Türkderm 2013;47:12-17. https://doi.org/10.4274/ turkderm.47.s2

11. Tye Din JA, Galipeau HJ, Agardh D. Celiac disease: a review of current concepts in pathogenesis, prevention, and novel therapies. Front Pediatr 2018;6:350. https:// doi.org/10.3389/fped.2018.00350

12. Bodis G, Toth $V$, Schwarting $A$. role of Human Leukocyte Antigens (HLA) in autoimmune diseases. Rheumatol Ther 2018;5:5-20. https://doi.org/10.1007/ s40744-018-0100-z

13. Pala FS, Tabakçıoğlu K, Algüneş Ç, Kurt Ömürlü I. Trakya'da yaşayan popülasyonun HLA-A, B ve DR sıklığı yönünden değerlendirilmesi ve balkan popülasyonları ile akrabalığının gösterilmesi. Trakya Ünv Tıp Fak Derg 2008;25:189-195.

14. Etiz P. Bölgemizdeki HLA (Human Lökosit Antijenleri) dağılımı. Yüksek Lisans Tezi. Çukurova Üniversitesi Sağlık Bilimleri Enstitüsü Mikrobiyoloji Anabilim Dalı, Adana, 2009.

15. Kayhan B, Kurtoglu EL, Taskapan H, et al. HLA-A, -B, -DRB1 allele and haplotype frequencies and comparison with blood group antigens in dialysis patients in the East Anatolia region of Turkey. Transplant Proc 2013;45:2123-2128. https://doi. org/10.1016/j.transproceed.2013.03.034

16. Patıroğlu $T$, Işık N, Öter $H$. Kayseri yöresinde doku antijenleri (HLA). Türk Nefroloji Diyaliz ve Transplantasyon Dergisi 1993;3:137-138.

17. Balkan E, Yaşar E, Doğan $H$. The diagnosis of human leukocyte antigen class I and class II allel in Eastern Anatolia Region. Van Tıp Derg 2019;26:162-166. 2019. https://doi.org/10.5505/vtd.2019.42042

18. Yeğin $\mathrm{O}$. Kronik böbrek yetmezliği olan hastalarda ve kontrollarda HLA antijenleri. Akdeniz Ünv Tıp Fak Dergisi 1988;2:131-137.

19. Ersoy Ş. Türk popülasyonunda doku grupları (HLA). Çocuk Sağlığı ve Hastalıkları Dergisi 1980;23:79-83.

20. Akman B. Tepecik Eğitim ve Araştırma Hastanesi doku tipleme laboratuvarı'na başvuran bireylerin insan lökosit antijen (HLA) allellerinin ve haplotiplerinin frekansları. Yüksek Lisans Tezi, İzmir Katip Çelebi Üniversitesi Sağlık Bilimleri Enstitüsü Tıbbi Biyoloji ve Genetik Anabilim Dalı, İzmir, 2016.

Etik kurul onayı: Çalışma için, Pamukkale Üniversitesi Tıp Fakültesi, Girişimsel Olmayan Klinik Araştırmalar Etik Kurulu'nun 27 Mayıs 2021 tarih ve 55651 sayılı kararı ile etik onayı alınmıştır.

Bu makale 2018 yılında Mehmet Akif Ersoy Üniversitesi'nde düzenlenen "I. Uluslararası Sağlık ve Yaşam Bilimleri Kongresi (IHSLC 2018)"nde sözlü bildiri olarak sunulmuştur. 